\title{
Cause Analysis and Treatment Measures of Urban Traffic Congestion
}

\author{
Zhijuan Wang
}

School of Economics and Management, Shandong Jiaotong University, Jinan 250357, China; wangzj1113@126.com

Keywords: Urban traffic congestion, cause analysis, treatment measures.

\begin{abstract}
The problem of urban traffic congestion was studied from the micro and macro aspects in the paper. Based on analysis the causes of urban traffic congestion, by combining the theory with practice, some measures which may solve the problem of urban traffic congestion have been put forward. The study not only provides strong support for the sustainable development of the urban social and economic, but also to provide beneficial reference to solve the problem of urban traffic congestion.
\end{abstract}

\section{Introduction}

In recent years, the traffic congestion in the city is very serious, and is becoming a city block. The reason is in many aspects. Firstly, it is in to work in the morning and evening peak traffic demand is much greater than the supply of traffic, which leads to frequent traffic congestion; secondly, major holidays, important activities of vehicles during the surge, or accidental traffic accident greatly reduces road traffic capacity, resulting in occasional traffic congestion ${ }^{[1]}$.

\section{Analysis of the causes of urban traffic congestion}

The development of vehicles and the development of the road is not coordinated. The pace of construction of urban road facilities behind the increase in vehicle speed of growth, road area rate of $6.2 \%$ increase year by year, while the vehicle is at a rate of $20.9 \%$ of fast growth ${ }^{[2]}$. The expansion of the capacity of transportation facilities, was completely offset by the rapid growth of vehicle.

Road network system is not perfect, the road network density is low. Network system is not perfect. The low density of urban road network influences the normal play of the whole function of urban road system, resulting in low traffic efficiency. It is the fundamental way to solve the urban traffic problems by reducing urban functions.

Mixed traffic accounts for a serious road. The biggest characteristic of domestic urban traffic is the mixed traffic flow. Besides the motor vehicles, there are non motor vehicles and pedestrians on the road, unlike foreign only motor vehicles on the road. For example, non motor vehicle traffic accounted for a large proportion in Jinan City traffic, resulting in mixed traffic phenomenon is more serious. In addition, the traffic right concept of people on the road is not strong. In Jinan City, the pavement is occupied seems to become the city of a serious illness. Because the city parking lot less, men have to occupy road for parking. The pavements are occupied by some small traders, bicycles have to ride on driveway, and pedestrians on the Road, will inevitably lead to serious mixed traffic. To ease the pressure of urban traffic, should strengthen the traffic behavior of the main bus. When the bus travel to $50 \%$ of the time, the utilization rate of urban roads is the highest, and pollution is at least $^{[3]}$.

The Peak period is elongated and the even hours are shortened. Day and night traffic peak phenomenon almost exists in each of the cities, namely there are the morning peak and evening rush 
traffic pressure every day. As early as the peak of the general 7:20-8:50, the evening peak appears at 17:00-18:00. The evening peak traffic flow is greater than the morning rush hour. At present, the city traffic has become a difficult problem, the traffic peak period has been elongated.

Slow development of public transport. Public transportation in rail transportation become a good choice to relieve the pressure on urban traffic, but the city orbit traffic in our country progresses slowly. Only a few large cities have Metro, and the operating mileage are short. Due to the terrain, Jinan City in the rail transit has just started construction, and Bus Rapid Transit has not formed a network. The Bus Rapid Transit accommodation road is not perfect, mixed with other vehicles in a part of the roads, and shared ride sites with ordinary buses. So the speed can not improve and play the advantage of Bus Rapid Transit.

Stereo traffic has not yet formed. At present, motor vehicles, non motor vehicles and pedestrians are all running in the same transport plane of the city. There are bicycles and pedestrians in every intersection, and the flat road area is limited, which consequentially lead to congestion.

In addition, some of the drivers self-discipline is poor, robs signal in the driving process, exists illegal parking and changing lane, and so on. Also, the number of the vehicles in the city growth too fast, and urban road construction and transformation are the reasons for reducing the traffic efficiency.

\section{Urban traffic congestion control measures}

The first is to do a good job in the city's urban planning. Planning must focus on the long term. It is very important to Vigorously develop exurb and small and medium-sized cities. Through the Rapid Transit such as light rail and Metro, the city should be led to spread all around to form some satellite towns. Each satellite city is self-contained, comfortable internal traffic flow, and connected main city with fast track connection. Fundamentally alleviate urban pass blocking problem.

Parking lot construction as the key point, the parking fee system needs to be improved. The parking problem is an important lever to control urban total motor vehicle travel. Urban parking too much, will promote the car use; urban parking is too small, will lead to car users of illegal parking increase, and the limited space of urban road will decrease. Therefore, we should improve and implement with construction of parking regulations, planning, arrangement and digging the potential of parking, try to resolve the parking problem. Parking facilities planning should assort with the overall urban planning and the urban comprehensive transportation planning.

In strengthening the construction of parking supply facilities in the city, at the same time, we should further strengthen the urban parking facilities management and restrict roadside parking. In possible secondary road and branch actively, reasonable implementation of curb parking charging system, cancel the roadside parking on the main roads and heavy traffic load road. In strengthening the supply management of the curb parking, the non allows the region or road parking should be eliminated, and combined with different locations and size of parking field existing parking capacity utilization. A short period of time (such as half an hour following) parking free should be advocated.

In addition, we should also establish the diversification of parking charges. In accordance with the standard which the areas of focus is higher than that of the central region, the central region is higher than the general area, with a regional curb temporary parking is higher than that of public parking field, the daytime is higher than nighttime, an appropriate increase in parking fees, will improve curb temporary parking turnover rate and utilization rate.

Comprehensive use of various modes of transportation and networking. There are many city traffic way, such as overhead, subway, light rail, ordinary bus , Bus Rapid Transit, bike etc. Each 
mode of transport exists rationally in a certain environment, and the traffic in the city should be according to the use and development of various transportation modes with Scientific Outlook on Development, which constitute a harmonious cooperative compensation relationship between them, in order to achieve efficient, energy saving, emission reduction, comfortable transportation. There are two key here, the first is the comprehensive use of various modes of transport, to solve the city traffic jam, not in only one or several modes of transport; second is regardless of the mode of transport that requires networking, not only is this mode of transport network, also called between several modes of transport network ${ }^{[4]}$. Pay attention to the construction of Metro and light rail. The light rail will also greatly reduce the city traffic pressure, urban and satellite city should be built between the light rail.

Earnestly implement the public transport priority. Public traffic transportation efficiency is the highest. Public traffic transportation not only can transport personnel in large numbers, and the fare is lower, so it is the absolute main force in the urban traffic. Bus priority is the first legislative priority, bus legislation in foreign countries is worth using for reference of the experience, a complete system, a simple level; and a clear function. Second is funding priority. Third is road resources allocation of priority. Urban land resource is limited, should not be a large number of allocated to the construction of high-rise buildings, but to ensure the land of road resource. In the allocation of road resources the priority should be assigned to the bus and give priority to the construction of urban road resources.

To make the residents bus priority, the city bus must accomplish. The circuit design should be reasonable. The bus can cover all local residents, as long as the concentrated region where needed, and convenient transfer. Each line must have a monitoring and feedback adjustment. Link scheduling and command line should operate orderly. Also reducing bus fares to attract students, the elderly and other groups who choose the public transportation. Priority with exclusive bus lanes, bus priority to ensure driving, accelerate the bus speed, reduce people's travel time. Public transportation should be as much as possible to meet passenger comfort and provide residents with safe, fast and economical way of travel. A bus station should meet the passengers good transfer, transfer distance is shorter, the convenient degree is high.

The large capacity of Bus Rapid Transit system must be improved as soon as possible. By giving priority to the development of public transport to solve the problem of traffic congestion, has been all over the world consensus. In view of the current situation, Bus Rapid Transit general speaking is more suitable for most of the city. So it is necessary to give full play to the advantages of rapid, in order to attract people to choose public transport as a way to travel.

Attention should be paid to the bicycle traffic. The bike and walking should be understand and treat as a transport mode of urban traffic. As a kind of urban traffic modes, it should be protected. The regions where appear to occupy the bike lanes and walking channel should rapidly construct the viaduct, let a lot of cars through the viaduct road, so as to reduce ground lane occupancy and restore bicycles and walking paths.

To improve microcirculation. In some road congestion nodes, as long as a "minor operation", you can effectively alleviate the traffic congestion. This cost is not much, but can play an immediate effect, in the short term effectively alleviate congestion on the sections of the road. To set up a channel often listening to the voice of the masses, timely find good advice. The government intervention in conjunction with the coordination, group decision making with all one's strength, will soon be one by one to solve the problem, the urban traffic has been greatly improved.

To develop intelligent traffic vigorously. Intelligent transportation, a common use is to control the traffic signal lamp. For example, you can induct intersection queue of vehicles the number, for red 
and green lights are automatically adjusted in a timely manner. When waiting for the north south direction of fewer vehicles, vehicles more east-west direction, intelligent transportation system can be to automatically reduce the north south direction of the green time and prolong the green time of east-west direction.

Intelligent Transportation System is also a prominent role is the implementation of virtual traffic. In order to ensure the scientific construction of urban traffic, and the feasibility of solving the problem of traffic jam in the city, it is necessary to implement the virtual traffic, which is intelligent transportation in to relieve traffic congestion in urban traffic ${ }^{[5]}$.

In addition, Intelligent Transportation System also includes advanced traveler information system, highway management system, public traffic management system, electronic toll collection system, event management system, and so on. The implementation of Intelligent Transportation System, its economic benefit, social benefit and environmental benefit is very obvious, so we should vigorously develop Intelligent Transportation System.

Other measures. Vigorously promote the car sharing. The development of car sharing can significantly reduce the amount of car ownership, to alleviate traffic congestion has an important role. Car sharing, not only bring convenience to individuals, but also bring great benefits to the community, car sharing provide a convenient for people to use cars too.

To implement the wrong time commuting system. To reform the current system of work and rest, implement the wrong job system, and adjust the need of social behavior according to the rules of the society. It is the represent of economic development and social progress, is a more efficient, more human nature of institutional arrangements, but also "work is to live a better life" the social objectives and concept of human embodiment.

Comprehensive transport hinge should be built in the city periphery, leading the traffic flow to the city circumambience, to guide the transfer of foreign vehicles into the bus, subway and other means of transportation into the city.

Accelerating the adjustment of urban space layout, by the use of residential, office, commercial, medical, education, financial multi functional composite development model, reduce the total amount of commuting, distance and time.

Optimization of urban road network structure, open up the broken road, road widening bottlenecks, ban illegal lane, to accelerate the construction of network microcirculation system, improve utilization of branch and the back alleys.

\section{References}

[1] Anthony Downs. Can traffic congestion be cured [J].The Washington Post, 2006, (4):955-974.

[2] XU Feng. The Analysis of Traffic Congestion in Cities Based on the Demand \&Supply Angle [J]. Logistics Engineering and Management, 2012, (10):83-84.

[3] CHEN Jing, PAN Quan-xiao. Several Paradoxes in the Urban Traffic Administration [J]. Future and Development, 2012, (8):35-37.

[4] Xu Yonghong. Network Governance of Urban Traffic Congestion [J]. Automation \& Instrumentation, 2015, (9):148-150.

[5] Jiang Yan; Liu Qiaoyun. Study of Congestion Problems and Counter measures for Urban Traffic [J]. Urban Roads Bridges \& Flood Control, 2015, (12):1-3. 